\title{
BDNF mediates improvements in executive function following a 1-year exercise intervention
}

\author{
Regina L. Leckie ${ }^{1,2 * t}$, Lauren E. Oberlin ${ }^{1,2+}$, Michelle W. Voss ${ }^{3}$, Ruchika S. Prakash ${ }^{4}$, \\ Amanda Szabo-Reed ${ }^{5}$, Laura Chaddock-Heyman ${ }^{6}$, Siobhan M. Phillips ${ }^{7}$, Neha P. Gothe ${ }^{8}$, \\ Emily Mailey ${ }^{9}$, Victoria J. Vieira-Potter ${ }^{10}$, Stephen A. Martin ${ }^{10}$, Brandt D. Pence $^{10}$, Mingkuan Lin ${ }^{11}$, \\ Raja Parasuraman ${ }^{12}$, Pamela M. Greenwood ${ }^{12}$, Karl J. Fryxell ${ }^{13}$, Jeffrey A. Woods ${ }^{10}$, \\ Edward McAuley ${ }^{6,10}$, Arthur F. Kramer ${ }^{6}$ and Kirk I. Erickson ${ }^{1,2,14}$
}

${ }^{1}$ Department of Psychology, University of Pittsburgh, Pittsburgh, PA, USA

${ }^{2}$ Center for the Neural Basis of Cognition, University of Pittsburgh, Pittsburgh, PA, USA

${ }^{3}$ Department of Psychology, University of lowa, lowa City, IA, USA

${ }^{4}$ Department of Psychology, Ohio State University, Columbus, OH, USA

${ }^{5}$ Cardiovascular Research Institute, University of Kansas Medical Center, Kansas City, KS, USA

${ }^{6}$ Beckman Institute for Advanced Science and Technology, University of Illinois, Champaign-Urbana, IL, USA

7 Department of Preventative Medicine, Northwestern University Medical School, Chicago, IL, USA

${ }^{8}$ Department of Kinesiology, Wayne State University, Detroit, MI, USA

${ }^{9}$ Department of Kinesiology, Kansas State University, Manhattan, KS, USA

${ }^{10}$ Department of Kinesiology and Community Health, University of Illinois, Champaign-Urbana, IL, USA

"Department of Neuroscience, George Mason University, Fairfax, VA, USA

12 Department of Psychology, George Mason University, Fairfax, VA, USA

${ }^{13}$ School of Molecular Biology, George Mason University, Fairfax, VA, USA

${ }^{14}$ Center for Neuroscience, University of Pittsburgh, Pittsburgh, PA, USA

\section{Edited by:}

Peter Hall, University of Waterloo, Canada

Reviewed by:

Lutz Jäncke, University of Zurich, Switzerland

Kristen M. Kennedy, University of Texas at Dallas, USA

*Correspondence:

Regina L. Leckie, Department of Psychology, University of Pittsburgh, 3417 Sennott Square, 210 S.

Bouquet Street, Pittsburgh, PA 15260, USA

e-mail: regina.leckie@gmail.com

tThese authors have contributed equally to this work.
Executive function declines with age, but engaging in aerobic exercise may attenuate decline. One mechanism by which aerobic exercise may preserve executive function is through the up-regulation of brain-derived neurotropic factor (BDNF), which also declines with age. The present study examined BDNF as a mediator of the effects of a 1-year walking intervention on executive function in 90 older adults (mean age $=$ 66.82). Participants were randomized to a stretching and toning control group or a moderate intensity walking intervention group. BDNF serum levels and performance on a task-switching paradigm were collected at baseline and follow-up. We found that age moderated the effect of intervention group on changes in BDNF levels, with those in the highest age quartile showing the greatest increase in BDNF after 1-year of moderate intensity walking exercise $(p=0.036)$. The mediation analyses revealed that BDNF mediated the effect of the intervention on task-switch accuracy, but did so as a function of age, such that exercise-induced changes in BDNF mediated the effect of exercise on task-switch performance only for individuals over the age of 71 . These results demonstrate that both age and BDNF serum levels are important factors to consider when investigating the mechanisms by which exercise interventions influence cognitive outcomes, particularly in elderly populations.

Keywords: BDNF, executive function, aging, exercise, physical activity, cognition, mediation analysis

\section{INTRODUCTION}

Decline in processing speed, memory, and executive function is a relatively widespread characteristic of aging (Li et al., 2001; Bishop et al., 2010; Silver et al., 2011; El Haj and Allain, 2012; Singh-Manoux et al., 2012; Woodard et al., 2012). Several neural mechanisms thought to support these cognitive processes become particularly vulnerable during the aging process (Burke and Barnes, 2006). For instance, brain-derived neurotrophic factor (BDNF) levels tend to decrease progressively with age (Lommatzsch et al., 2005; Ziegenhorn et al., 2007; Driscoll et al., 2012) and correlate with age-related reductions in hippocampal volume (Erickson et al., 2010a). BDNF facilitates neural repair
(Yang et al., 2014), induces long-term potentiation (Diógenes et al., 2011), enhances learning and memory (Pang and Lu, 2004; Bekinschtein et al., 2014), and promotes synaptic plasticity and neurogenesis (Oliff et al., 1998; Lu, 2003; Vaynman et al., 2004). The beneficial effects of BDNF on brain health and cognition may be especially relevant for older adults, who are susceptible to physiological changes that interfere with neural processes and cognitive function. For instance, marked increases in blood pressure and inflammatory load occur in older adulthood, both of which have been independently linked to dementia risk and decline in cognitive function (Schmidt et al., 2002; Singh and Newman, 2011). Thus, there is an increased presence of 
factors that compromise cognitive function in older adults, with a contemporaneous decrease in known mechanisms that support advantageous brain and cognitive health. Therefore, efforts to increase BDNF, particularly in older aged individuals, could play an important role in the preservation of cognitive function.

Fortunately, exercise may be an effective approach to preserve and improve cognitive function and brain health in late adulthood. For example, randomized clinical trials have found that moderate-intensity exercise improves memory and executive function (Kramer et al., 1999a; Colcombe and Kramer, 2003; Smith et al., 2010) increases prefrontal cortex (Colcombe et al., 2006) and hippocampal volume (Erickson et al., 2011), and influences brain network connectivity (Voss et al., 2010a). Crosssectional and epidemiological studies have supported these results and demonstrate that higher fitness levels and greater amounts of physical activity are associated with greater gray matter volumes (Erickson et al., 2010b; Weinstein et al., 2012; Benedict et al., 2013), white matter integrity (Gow et al., 2012; Gons et al., 2013; Tian et al., 2014), reduced brain atrophy rates (Gow et al., 2012; Smith et al., 2014), and reduced risk of cognitive impairment and dementia (Podewils et al., 2005; Larson et al., 2006; Sofi et al., 2011). Yet, the mechanisms by which exercise improves or maintains brain health in humans remain poorly understood, but likely include changes in inflammation, insulin resistance, as well as central changes in serotonin, dopamine, or other neurotransmitters.

Increased expression of BDNF may be another mechanism by which exercise positively influences cognitive and brain function. For example, in rodents, exercise increases BDNF expression in the striatum (Marais et al., 2009), hippocampus (Aguiar et al., 2011), and cortex (Neeper et al., 1996) and an exercise-induced up-regulation of BDNF, along with its receptor tyrosine kinase (Li et al., 2008), mediates the effects of exercise on cognition (Gómez-Pinilla et al., 2002; Vaynman et al., 2004; Van Praag et al., 2005; Stranahan et al., 2009; Creer et al., 2010; Bechara and Kelly, 2013). Unfortunately in humans the effect of exercise on serum BDNF is more equivocal (Zoladz and Pilc, 2010). Acute bouts of exercise increase serum BDNF levels, which, in turn, are associated with improvements in cognitive performance (Knaepen et al., 2010; Ströhle et al., 2010; Heyman et al., 2012; Coelho et al., 2013). However, more chronic and longer-term exercise programs have not reliably demonstrated increases in BDNF levels (Baker et al., 2010; Erickson et al., 2011; Ruscheweyh et al., 2011). Despite these discouraging effects of exercise interventions, exercise-induced changes in hippocampal volume (Erickson et al., 2011) and brain connectivity (Voss et al., 2013) were correlated with percent change in serum BDNF levels. These findings suggest that serum BDNF levels may be an important biomarker for brain and cognitive health, but whether BDNF mediates the positive effects of exercise on cognitive performance remains a matter of speculation.

Here, we examine whether exercise-induced changes in serum BDNF mediates the effect of a randomized exercise intervention on executive function. Specifically, we assessed effects on task-switch performance, a cognitive task largely susceptible to age-related shifts in performance speed and accuracy (Salthouse et al., 1998; Kray and Lindenberger, 2000; Cepeda et al., 2001;
Jimura and Braver, 2010; Gazes et al., 2012). This task is considered a measure of executive control and is supported primarily by the prefrontal and parietal cortices (Sohn et al., 2000; Braver et al., 2003; Aron et al., 2004; Gold et al., 2010), regions that experience preferential degeneration with advancing age (Sowell et al., 2003; Salat et al., 2005; Driscoll et al., 2009). Because BDNF levels decline with age (Lommatzsch et al., 2005; Burke and Barnes, 2006; Ziegenhorn et al., 2007), and is found in cortical regions that likely support task-switch performance (Podewils et al., 2005; Aguiar et al., 2011; Diógenes et al., 2011), we reasoned that age might be an important moderator of the effects of exercise on BDNF and task-switch performance.

Prior studies examining the effects of exercise on serum BDNF have used age as a covariate rather than modeling age as an interaction term. Yet, several studies and meta-analyses suggest that the positive effects of exercise on cognitive performance may be magnified at older ages (Etnier et al., 2007; Smith et al., 2010) while others have found that age-related losses in gray matter volume and $n$-acetylaspartate levels were mitigated by higher fitness levels (Colcombe et al., 2003; Erickson et al., 2012). These and other studies (Adlard et al., 2005; Knaepen et al., 2010) suggest that age might be moderating an effect of exercise on serum BDNF levels.

The current study examined the effects of a 12-month randomized exercise intervention on serum BDNF and taskswitching performance in older adults. We predicted that exercise-induced changes in serum BDNF would mediate the effects of the exercise intervention on task-switch performance. However, we also predicted that age would moderate the effect of the intervention on BDNF levels, such that the oldest adults in the exercise group would show greater increases in BDNF than their younger counterparts.

\section{METHOD \\ PARTICIPANTS}

One-hundred and seventy-nine participants were randomly assigned to either a walking exercise or stretching-toning control group prior to the start of the intervention. Of the 179 participants, 106 had complete blood data collected at baseline and post-intervention for BDNF assays. Additionally, 13 participants were missing $B D N F$ genetic polymorphism data and were excluded from the analysis. We also excluded one participant who was ill at the time of blood draw. Our final sample in BDNF analyses consisted of 92 participants. There were an additional two individuals missing task-switching data (one from each group), so all analyses conducted with the task-switch data used a sample of 90 participants. Excluded participants did not differ in demographic characteristics or baseline fitness level from those included $(p>0.05)$. The sample and results from this intervention have been previously reported, where hippocampal volume (Erickson et al., 2011), brain connectivity (Voss et al., 2010a,b, 2013) white matter integrity and adherence to the intervention (McAuley et al., 2011) were examined. The analyses and results reported in the current study have not been previously examined, nor published.

Community-dwelling older adults were recruited from the local community of Urbana-Champaign, Illinois. Eligible 
participants had to (i) demonstrate strong right handedness (Oldfield, 1971), (ii) be between the ages of 55 and 80, (iii) score $\geq 51$ on the modified Mini-Mental Status Examination (Stern et al., 1987), (Singh-Manoux et al., 2012), score $<3$ on the Geriatric Depression Scale to rule out possible depression (Yesavage and Sheikh, 1986), ( $v$ ) have normal color vision, (vi) have a corrected visual acuity of at least 20/40, (vii) have no history of neurological diseases or infarcts, including Parkinson's disease, Alzheimer's disease, multiple sclerosis, or stroke, (viii) have no history of major vasculature problems, including cardiovascular disease or diabetes, $(i x)$ obtain consent from their personal physician, and $(x)$ sign an informed consent form approved by the University of Illinois. In addition, all participants had to report being currently sedentary, which was defined as having been physically active for $30 \mathrm{~min}$ or more no more than two times in the last 6 months. Participants were compensated for their participation. The Institutional Review Board of the University of Illinois approved the study and all participants gave written informed consent prior to participating.

After completion of the initial blood draw, an MRI session (results not included here), and fitness assessment, participants were randomized to the aerobic walking group $(n=47)$ or to the stretching-toning control group $(n=45)$. Demographic information can be found in Table $\mathbf{1 .}$

\section{AEROBIC FITNESS ASSESSMENT}

Maximal oxygen uptake $\left(\mathrm{VO}_{2 \max }\right)$ was used as an objective measure of baseline cardiorespiratory fitness. Participants were required to obtain consent from their personal physician before cardiorespiratory fitness testing was conducted. As detailed by Voss et al. (2010a) assessment of cardiorespiratory fitness was determined using graded maximum exercise testing on a motordriven treadmill with continuous monitoring of respiration, heart rate, and blood pressure by a cardiologist and nurse (Voss et al.,

Table 1 | Demographics, fitness, and BDNF.

\begin{tabular}{|c|c|c|c|}
\hline Variable & $\begin{array}{l}\text { Total sample } \\
\qquad N=92\end{array}$ & $\begin{array}{l}\text { Walking group } \\
\qquad N=47\end{array}$ & $\begin{array}{c}\text { Control group } \\
\qquad N=45\end{array}$ \\
\hline$\%$ Men & $35.9 \%$ & $31.90 \%$ & $40.00 \%$ \\
\hline Age (years) & $66.82(5.59)$ & $67.23(5.39)$ & $66.38(5.83)$ \\
\hline \multicolumn{4}{|l|}{ EDUCATION \% } \\
\hline High School & $19.6 \%$ & $19.1 \%$ & $20 \%$ \\
\hline Part & $30.4 \%$ & $36.2 \%$ & $24.4 \%$ \\
\hline \multicolumn{4}{|l|}{ College/Nocational } \\
\hline Bachelor's Degree & $16.3 \%$ & $12.8 \%$ & $20 \%$ \\
\hline Master's Degree & $21.7 \%$ & $23.4 \%$ & $20 \%$ \\
\hline $\mathrm{PhD}$ or Equivalent & $12 \%$ & $8.5 \%$ & $15.6 \%$ \\
\hline $\mathrm{VO}_{2 \max }(\mathrm{mL} / \mathrm{kg})$ & $21.51(4.68)$ & $21.22(4.62)$ & $21.82(4.78)$ \\
\hline $\begin{array}{l}\text { Pre-intervention } \\
\text { BDNF (pg/mL) }\end{array}$ & $21,909.96$ (9147.95) & $21,736.91$ (9768.31) & $22,090.69(8558.71)$ \\
\hline $\begin{array}{l}\text { Post-intervention } \\
\text { BDNF (pg/mL) }\end{array}$ & $22,897.03$ (8293.85) & $24,067.78$ (7814.90) & $21,674.24(8684.70)$ \\
\hline $\begin{array}{l}\text { BDNF met allele } \\
\text { carriers }\end{array}$ & 7 & 2 & 5 \\
\hline
\end{tabular}

Demographic information comparing the two intervention groups: walking intervention, stretching and toning control. 2010a, 2013). During the assessment, subjects walked at a speed slightly faster than their normal walking pace with increasing graded increments of $2 \%$ every 2 min. Oxygen uptake was measured at 30-s intervals until a $\max \mathrm{VO}_{2}$ was attained or to the point of test termination due to exhaustion. $\mathrm{VO}_{2 \max }$ was defined as the highest recorded $\mathrm{VO}_{2}$ value when two of three criteria were satisfied: (1) a plateau in $\mathrm{VO}_{2}$ peak between two or more workloads, (2) a respiratory exchange ratio $>1.00$, or (3) a heart rate equivalent to their age predicted maximum (i.e., 220-age). $\mathrm{VO}_{2 \max }$ scores are expressed in units of milliliters per kilogram per minute $(\mathrm{ml} / \mathrm{kg} / \mathrm{min})$, after controlling for height and weight of the individual.

\section{TRAINING PROTOCOL}

\section{Aerobic exercise condition}

For the aerobic exercise program, a trained exercise leader supervised all sessions. As described by McAuley et al. (2011) and Erickson et al. (2011), participants started by walking for $10 \mathrm{~min}$ and increased walking duration weekly by 5 -min increments until a duration of $40 \mathrm{~min}$ was achieved at week 7 . Participants walked for $40 \mathrm{~min}$ per session for the remainder of the program. All walking sessions started and ended with approximately $5 \mathrm{~min}$ of stretching for the purpose of warming up and cooling down. Participants wore heart rate monitors and were encouraged to walk in their target heart rate zone, which was calculated using the Karvonen method (Strath et al., 2000) according to the resting and maximum heart rates achieved during the baseline maximal graded exercise test. The target heart rate zone was $50-60 \%$ of the maximum heart rate reserve for weeks $1-7$ and $60-75 \%$ for the remainder of the program. Participants in the walking group completed an exercise log at each exercise session. Every 4 weeks, participants received written feedback forms that summarized the data from their logs. Participants with low attendance and/or a low exercise heart rate were encouraged to improve their performance in the following month.

\section{Stretching and toning control condition}

For the stretching and toning control program, all sessions were led and monitored by trained exercise leaders. All classes started and ended with warm-up and cool-down stretching. During each class, participants engaged in four muscle-toning exercises using dumbbells or resistance bands, two exercises designed to improve balance, one yoga sequence, and one exercise of their choice. To maintain interest, a new group of exercises was introduced every 3 week. During the first weeks, participants focused on becoming familiar with the new exercises, and during the second and third weeks they were encouraged to increase the intensity by using more weight or adding more repetitions. Participants in the stretching and toning control group also completed exercise logs at each exercise session and received monthly feedback forms. They were encouraged to exercise at an approximate intensity of 13-15 on the Borg Rating of Perceived Exertion scale (Borg, 1985) and to attend as many classes as possible.

\section{SERUM BDNF ASSAY}

Blood was collected at baseline before the intervention and again immediately after the completion of the program. Blood sampling 
for BDNF analysis was performed approximately 1 week before the cognitive testing session. Fasted subjects reported to the laboratory at $0600-0800 \mathrm{~h}$, at which time blood from the antecubital vein was collected in serum separator tubes (Becton Dickinson). The blood samples were kept at room temperature for $15 \mathrm{~min}$ to allow for clotting, after which the samples were centrifuged at $1100 \times \mathrm{g}$ at $4^{\circ} \mathrm{C}$ for $15 \mathrm{~min}$. Serum was then harvested, aliquoted, and stored at $-80^{\circ} \mathrm{C}$ until analysis. Serum BDNF was quantified using an enzyme-linked immunosorbant assay (Human BDNF Quantikine Immunoassay, DBD00, R\&D Systems) according to the manufacturer's instructions.

\section{BDNF GENOTYPING}

We used the BuccalAmp ${ }^{\mathrm{TM}}$ DNA Extraction Kit from Epicentre Biotechnologies (Madison, WI USA). Buccal cells were collected from Puritan sterile cheek swabs after rinsing the mouth with tap water. The rs6265 SNP was assayed by a combination of nested PCR and melting-curve analysis with $\mathrm{T}_{\mathrm{m}}$-shift primers (Wang et al., 2005). The DNA fragment was preamplified from genomic DNA (300 bp) and used as a template for second round (allelespecific) PCR on a Bio-Rad MyiQ thermal cycler, which allows automated melting temperature analysis of the PCR products. One allele-specific primer was designed with a $5^{\prime} \mathrm{GC}$ tail, resulting in an easily detectable increase in the melting temperature of the PCR product. For rs6265, the forward and reverse primers used in the first PCR were $5^{\prime}$ ACTCTGGAGAGCGTGAATGG $3^{\prime}$ and $5^{\prime}$ CCAAAGGCACTTGACTACTGA $3^{\prime}$. In the second round PCR, the primer specific to the " $G$ " allele (val) was 5' GCGGGCAGGGCGGCTCATCCAA CAACTCTTCTAACAC $3^{\prime}$, the primer specific to the "A" allele (met) was $5^{\prime}$ TCATCCAACAACTCTTCTACCAT $3^{\prime}$ and the common primer was $5^{\prime}$ CCAAGGCAGGTTCAAG 3'. Genetic data was analyzed using a dominance model such that Met carriers were combined into a single group.

\section{COGNITIVE ASSESSMENT}

The task-switching paradigm is frequently used to assess executive processes (Kramer et al., 1999a; Kray and Lindenberger, 2000; Gratton et al., 2009; Gold et al., 2010; Jimura and Braver, 2010), including cognitive flexibility and inhibition (Verstynen et al., 2012). The task-switch paradigm was administered as part of a larger battery of tasks, but was selected for the present study because (1) it assesses executive functioning and (2) our previous studies have shown that this task is sensitive to exercise interventions (Kramer et al., 1999a,b). Therefore, we selected this task because it met criteria for testing mediation.

As described in Voss et al. (2010a), participants utilized colorbased cues to determine whether they were to judge whether a number was odd or even, or whether it was low or high (i.e., smaller or larger than 5). The numbers were presented individually for $1500 \mathrm{~ms}$ against a pink or blue background. If the background was blue, participants had to determine whether the number was high (" $\mathrm{X}$ " key) or low (" $Z$ " key). If the background was pink, participants were to report whether the number was odd ("N" key) or even ("M" key). In both cases, participants were asked to answer as quickly as possible (Voss et al., 2010a). Participants completed a practice block followed by two blocks of individually presented tasks, one block consisted of only the "high or low" task, and the other consisted of only the "odd or even" task. This was followed by a switching block, which included 120 trials with the task in each trial chosen randomly. In this block, some trials were repeated, referred to here as "repeat trials," and some trials switched between the two conditions, referred to here as "switch trials" (see Figure $\mathbf{1}$ for task depiction).

Accuracy (\% correct) and reaction time (RT) served as indices of performance on the task-switch test. Accuracy (\% correct) and time (RT) was recorded separately for single trials, repeat trials within the mixed block, and switch trials within the mixed block. Local switch cost, the difference between repeat trials (when the preceding trial involved the same task) and switch trials (when the preceding trial involved a different task) was calculated for both RT and accuracy (Verstynen et al., 2012). Additionally, global switch cost, the difference between switch trials and single task trials, was calculated for RT and accuracy.

\section{STATISTICAL ANALYSIS}

All variables were tested for normality and skew. To assess whether age was inversely associated with serum BDNF, we conducted a multivariable linear regression analysis. $B D N F$ genotype was included as a covariate in the model to adjust for effects of the val66met polymorphism on BDNF serum concentrations.

To examine whether the effect of exercise group (walking; stretching) on serum BDNF varied as a function of age, multivariable linear regression was employed using the bootstrap method with 10,000 resampling iterations. Therefore, main effects and interaction effects were estimated from the resampled data repeatedly drawn from the original dataset with replacement. Within the regression model, pre-intervention serum BDNF was included as a covariate to account for any group-level differences in serum BDNF at baseline. Gender and the BDNF val66met polymorphism were also adjusted for in the model. Exercise group and age were entered as predictor terms to determine whether age and group independently predicted change in serum BDNF. We also included an age $\times$ group interaction in order to test whether age moderated the effect of exercise group on change in serum BDNF.

We also predicted that age would moderate the association between exercise group and cognitive performance postintervention. To test this hypothesis, we used multivariable linear regression adjusting for gender, years of education, baseline serum BDNF, the BDNF val66met polymorphism, and baseline cognitive performance. Thus, rather than modeling withinsubject changes in cognitive performance, we assessed grouplevel differences in performance post-intervention, accounting for individual differences in performance at baseline. Again, bootstrapping was applied to the regression model, using 10,000 iterations. Also entered was group, age as a continuous variable, and their interaction product. A statistical threshold of $p<0.05$ was used to determine significance for the linear regression analyses. Significant interactions revealed by the linear regression analyses were then subjected to repeated measures analysis of variance tests to assess within-subject changes from pre to post-intervention.

Finally, conditional process modeling was used to examine the conditional nature by which exercise group predicts cognitive function following the 1-year intervention. Using this procedure, 


\section{Single Task Condition}

2 task blocks, 60 trials in each

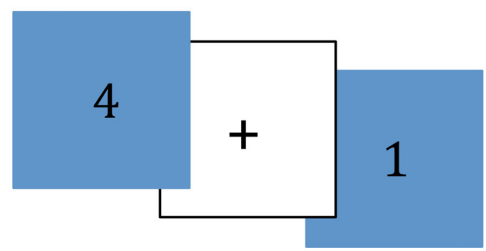

Block 1

\section{Mixed Condition}

1 task block, 120 trials

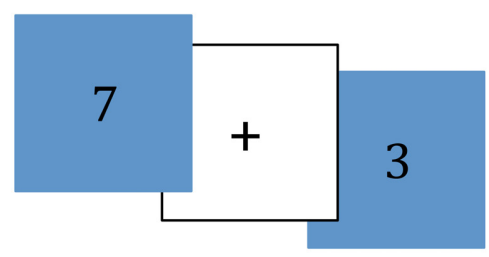

Repeat Trial

FIGURE 1 | Display of the task-switch paradigm. Participants were instructed to respond to a number between 1 and 9 (except for 5) that appeared centrally located on the computer screen. The

background color (blue/pink) cued them as to the task they would
= higher/lower than 5

- = even/odd

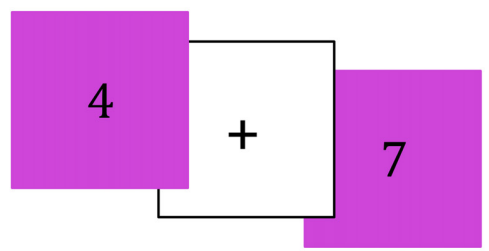

Block 2

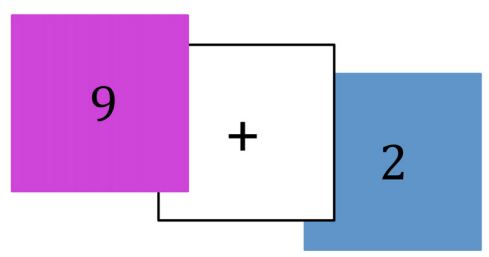

Switch Trial

do (Pink: even/odd; Blue: higher/lower than 5). In the single task condition participants were presented with blocks of a single task whereas in the mixed condition the two conditions were randomly presented. we examined whether BDNF serum levels mediated the relationship between exercise group and cognitive performance, and whether the indirect effect of exercise group on cognitive performance through serum BDNF varied as a function of age. This technique estimates the mediating effect of serum BDNF on the relationship between exercise group and task-switch performance, while accounting for moderating effects of age on (1) the effect of exercise group on serum BDNF and (2) the direct effect of exercise group on task-switch performance. The model format and analyses were conducted using the PROCESS macro by Hayes (2013) in SPSS. This method provided an estimation of both the direct and indirect pathways, resulting in the calculation of 95\% confidence intervals (CI) for both direct and indirect effects (see Figure 2 for model depiction). The regression coefficients are displayed in unstandardized form, as the bootstrapped CI's correspond to the unstandardized effects rather than the standardized effects. Mediation results are considered significant if the CI's do not contain 0 .

\section{RESULTS}

\section{SUBJECT CHARACTERISTICS AT BASELINE}

The exercise groups did not significantly differ in age, gender, years of education, serum BDNF, or $\mathrm{VO}_{2 \max }$ at baseline (all $p>$ 0.05) (see Table 1). Additionally, there were no significant differences between groups on task switch performance indices at baseline (all $p>0.05$; see Table 2 for task switch accuracy and reaction time data pre and post-intervention).

\section{AGE MODERATES THE EFFECT OF EXERCISE ON CHANGE IN SERUM BDNF}

The $B D N F$ val66met polymorphism was not related to serum BDNF at baseline $(r=0.018 ; p=0.868)$. Nonetheless, in the regression analyses described below we continued to control for $B D N F$ val66met variation because several prior studies have indicated a small, but significant, relation between serum BDNF and the BDNF val66met polymorphism (Lang et al., 2009). We also found that females had significantly higher levels of serum BDNF at baseline in this sample $(r=0.266 ; p=0.010)$ and therefore included gender as a covariate in the analyses below. Consistent with our hypothesis, older ages were associated with lower serum BDNF levels prior to the start of the intervention $(t=-3.501$; $p=0.001$ ), after controlling for gender and the BDNF val66met polymorphism.

Collapsed across the intervention and control groups, age did not predict change in serum BDNF over the 1 -year period $(B=-77.69 ; p=0.489)$. Similarly, holding age constant, there was not a main effect of exercise group on change in serum BDNF following the intervention, although the association was trending $(B=2652.27 ; p=0.084)$. However, the lack of main effects was qualified by a significant interaction between age and exercise 


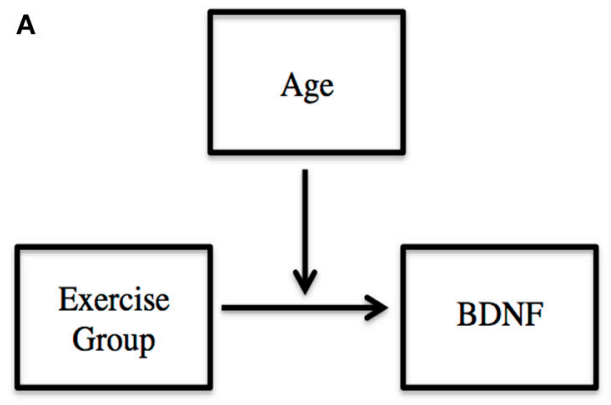

Moderation Model: Effect of exercise group on BDNF serum levels as a function of age

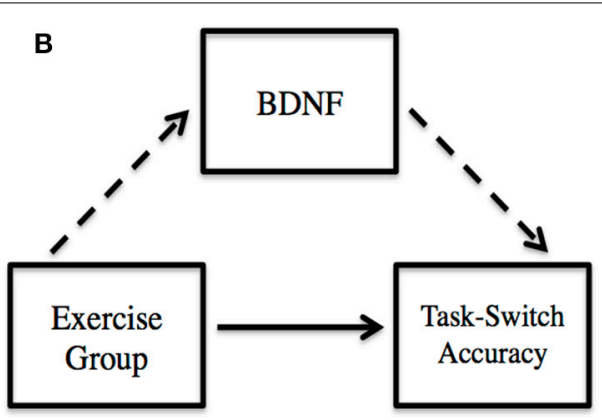

Mediation Model: Effect of exercise group on Task-Switch accuracy cost as a function of BDNF serum levels

C

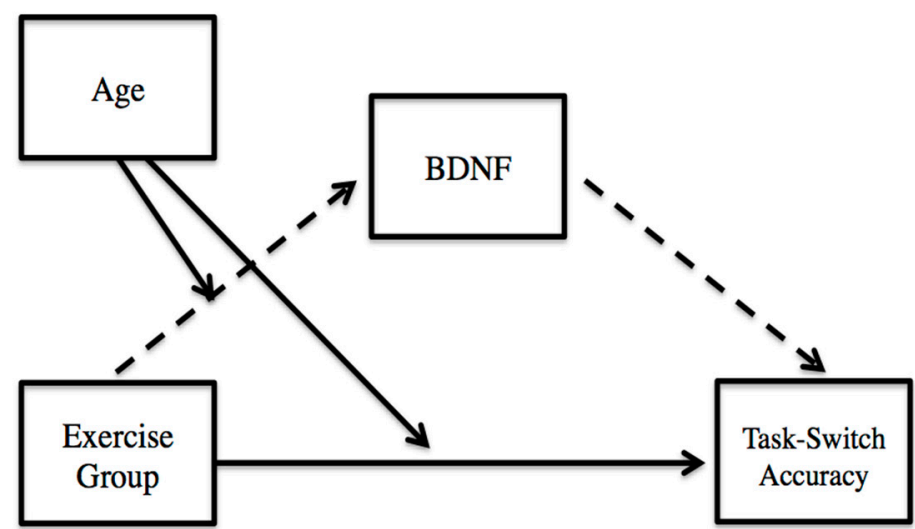

Moderated Mediation Model: Mediating effect of BDNF serum levels on the effect of exercise group on Task-Switch accuracy cost as a function of age

FIGURE 2 | Moderated mediation model. (A) Moderation Model: Effect of exercise group on BDNF serum levels as a function of age. (B) Mediation Model: Effect of exercise group on Task-Switch accuracy cost as a function of BDNF serum levels. Note: Solid arrow indicates direct pathway; Dashed arrow indicates indirect pathway. (C) Moderated Mediation Model: Mediating effect of BDNF serum levels on the effect of exercise group on Task-Switch accuracy cost as a function on age. Note: Solid arrow indicates moderation; Dashed arrow indicates mediation. group on change in serum BDNF $(B=471.95 ; p=0.036)$ (see Table 3). Specifically, across the 1-year intervention, the stretching and toning group showed a decline in BDNF levels for the oldest individuals. In contrast, there was a positive linear relationship between age and serum BDNF in the walking group, indicating that older aged individuals experienced the greatest increase in BDNF following 1-year of moderate intensity walking exercise (see Figure 3B).

For further exploration of this interaction, we used repeated measures analysis of variance and divided the sample into higher and lower aged individuals using the median value for age (Md age $=65)$. Serum BDNF at baseline and serum BDNF post-intervention were entered as the within subjects factor, age and exercise group were entered as between subjects factors, and BDNF genotype and gender were entered as covariates. Consistent with the results from the regression, participation in the walking group offset an age-related reduction in BDNF levels $\left(F=5.45 ; p=0.022 ; \eta_{p}^{2}=0.060\right)$ (see Figure 3$)$. In particular, 12 months of moderate intensity walking exercise increased serum BDNF levels among adults older than 65 years of age, while similarly aged individuals in the non-aerobic condition showed a decrease in serum BDNF over the 12-month intervention period.

\section{AGE MODERATES THE EFFECT OF EXERCISE ON TASK-SWITCH PERFORMANCE}

There was not a significant relation between education, baseline serum BDNF, or the BDNF val66met polymorphism and performance for any of the task switch outcomes (all $p>0.05$ ). However, males had a smaller global accuracy cost at baseline $(r=-0.210 ; p=0.046)$, so gender was used as a covariate in the regression model below. Further, although education and BDNF serum and genotype were not significantly related to task-switch outcomes, we included these variables as covariates in the regression model since prior research has reported effects of education and BDNF on cognitive outcomes in late adulthood (Albert et al., 1995; Erickson et al., 2008; Gunstad et al., 2008). Including these variables in the model provides a more conservative estimate of the associations between exercise group, change in serum BDNF, and change in task-switch performance. 
Table 2 | Task-switch performance.

\begin{tabular}{|c|c|c|c|}
\hline Variable & $\begin{array}{c}\text { Total sample } \\
\qquad N=90\end{array}$ & $\begin{array}{l}\text { Walking group } \\
\qquad N=46\end{array}$ & $\begin{array}{c}\text { Control group } \\
\qquad N=44\end{array}$ \\
\hline $\begin{array}{l}\text { Pre-intervention } \\
\text { single accuracy }\end{array}$ & $92.71 \%$ & $93.13 \%$ & $92.27 \%$ \\
\hline $\begin{array}{l}\text { Post-intervention } \\
\text { single accuracy }\end{array}$ & $96.48 \%$ & $96.47 \%$ & $96.50 \%$ \\
\hline $\begin{array}{l}\text { Pre-intervention } \\
\text { repeat accuracy }\end{array}$ & $82.49 \%$ & $83.33 \%$ & $81.64 \%$ \\
\hline $\begin{array}{l}\text { Post-intervention } \\
\text { repeat accuracy }\end{array}$ & $90.17 \%$ & $92.36 \%$ & $87.87 \%$ \\
\hline $\begin{array}{l}\text { Pre-intervention } \\
\text { switch accuracy }\end{array}$ & $77.02 \%$ & $78.11 \%$ & $75.91 \%$ \\
\hline $\begin{array}{l}\text { Post-intervention } \\
\text { switch accuracy }\end{array}$ & $88.86 \%$ & $91.13 \%$ & $86.49 \%$ \\
\hline $\begin{array}{l}\text { Pre-intervention local } \\
\text { accuracy cost }\end{array}$ & $-6.60 \%$ & $-6.11 \%$ & $-7.10 \%$ \\
\hline $\begin{array}{l}\text { Post-intervention } \\
\text { local accuracy cost }\end{array}$ & $-1.60 \%$ & $-1.48 \%$ & $-1.73 \%$ \\
\hline $\begin{array}{l}\text { Pre-intervention } \\
\text { global accuracy cost }\end{array}$ & $-15.69 \%$ & $-15.02 \%$ & $-16.36 \%$ \\
\hline $\begin{array}{l}\text { Post-intervention } \\
\text { global accuracy cost }\end{array}$ & $-7.96 \%$ & $-5.45 \%$ & $-10.58 \%$ \\
\hline $\begin{array}{l}\text { Pre-intervention } \\
\text { single RT (ms) }\end{array}$ & 774.64 (105.35) & $774.62(96.47)$ & 774.67 (114.82) \\
\hline $\begin{array}{l}\text { Post-intervention } \\
\text { single RT (ms) }\end{array}$ & 758.97 (106.48) & 757.29 (99.94) & 760.75 (113.34) \\
\hline $\begin{array}{l}\text { Pre-intervention } \\
\text { repeat RT (ms) }\end{array}$ & 994.96 (197.07) & $1000.27(204.64)$ & 989.69 (191.36) \\
\hline $\begin{array}{l}\text { Post-intervention } \\
\text { repeat RT (ms) }\end{array}$ & 986.17 (144.69) & $991.13(136.40)$ & $980.88(154.47)$ \\
\hline $\begin{array}{l}\text { Pre-intervention } \\
\text { switch RT (ms) }\end{array}$ & $1356.34(194.80)$ & 1358.90 (175.54) & $1353.79(214.32)$ \\
\hline $\begin{array}{l}\text { Post-intervention } \\
\text { switch RT (ms) }\end{array}$ & 1290.29 (239.18) & $1298.98(204.85)$ & $1281(273.27)$ \\
\hline $\begin{array}{l}\text { Pre-intervention local } \\
\text { RT cost (ms) }\end{array}$ & 361.37 (218.37) & 358.63 (225.64) & $364.10(213.37)$ \\
\hline $\begin{array}{l}\text { Post-intervention } \\
\text { local RT cost (ms) }\end{array}$ & 304.12 (184.92) & 307.86 (143.17) & $300.12(221)$ \\
\hline $\begin{array}{l}\text { Pre-intervention } \\
\text { global RT cost (ms) }\end{array}$ & 400.86 (163.48) & 404.65 (148.15) & 397.06 (179.12) \\
\hline $\begin{array}{l}\text { Post-intervention } \\
\text { global RT cost (ms) }\end{array}$ & 397.70 (153.57) & 407.18 (140.35) & 387.58 (167.59) \\
\hline
\end{tabular}

Demographic information comparing the two intervention groups: walking intervention, stretching, and toning control.

RT, Reaction Time; ms, milliseconds.

The linear regression model showed that there was not a main effect of group on global accuracy percent cost [(switch trial accuracy-single trial accuracy)/single trial accuracy] post-intervention $(B=5.952 ; p=0.097)$, although the relation was trending. These results suggest that the control group demonstrated a marginally greater deficit in accuracy between single and switch trials relative to those in the walking group at post-intervention. Additionally, there was not a significant main effect of age on global accuracy cost $(B=-0.055 ; p=0.868)$. But, there was an interaction between age and exercise group
Table 3 | Age moderates effect of exercise group on BDNF serum levels at post-intervention.

\begin{tabular}{lccccc}
\hline & $\boldsymbol{B}$ & $\boldsymbol{S E}$ & $\boldsymbol{p}$ & LLCI & ULCI \\
\hline COVARIATES & & & & & \\
Baseline serum BDNF & $0.473^{* *}$ & 0.109 & 0.0001 & 0.256 & 0.684 \\
BDNF genotype & 1152.29 & 2055.91 & 0.560 & -2730.59 & 5415.26 \\
Gender & 1137.57 & 1834.59 & 0.535 & -2555.65 & 4599.24 \\
MAIN EFFECTS & & & & & \\
Age & -77.69 & 112.27 & 0.490 & -303.22 & 142.03 \\
Exercise group & 2652.27 & 1472.59 & 0.078 & -373.40 & 5429.23 \\
INTERACTION & & & & & \\
Exercise group $\times$ Age & $471.95 *$ & 1.735 & 0.039 & 26.261 & 919.647 \\
\hline
\end{tabular}

Age as moderator of the effect of exercise group on serum BDNF postintervention. Coefficients are unstandardized B-values calculated from bootstrap permutation of 10,000 iterations.

$L L C l$, lower-level confidence interval; ULCI, upper-level confidence interval. ${ }^{*} p<0.05 ;{ }^{* *} p<0.01$.

on changes in global accuracy cost $(B=1.645 ; p=0.026)$ (see Table 4). Decomposing this interaction revealed that global accuracy cost remained constant over the 12 month period across all ages within the aerobic exercise group. In contrast, within the stretching and toning control group, there was an age-related increase in percent accuracy cost following the 1-year intervention. Thus, while the magnitude of the global accuracy cost remained constant across all ages in the walking group, older aged individuals within the non-aerobic condition demonstrated a larger cost on performance following the 12-month intervention.

We probed the interaction using a repeated measures analysis of variance, and divided the sample into higher and lower aged individuals using the median age value $(\mathrm{Md}$ age $=65)$. Global accuracy cost at baseline and post-intervention were entered as the within subjects factor, age and exercise group were entered as between subjects factors, and gender, years of education, $B D N F$ genotype, and serum BDNF at baseline were included as covariates. In accordance with the results from the regression analysis, age-related reduction in task performance was negated by participation in the aerobic exercise condition $(F=5.19 ; p=0.025$; $\left.\eta_{p}^{2}=0.064\right)$.

In contrast, there was not a significant main effect of exercise group $(B=0.602 ; p=0.633)$ on local accuracy (switch accuracy - repeat accuracy/repeat accuracy) cost. There was also a non-significant relation between age and local accuracy cost $(B=0.156 ; p=0.103)$ and a non-significant age $\times$ exercise group interaction on local accuracy cost $(B=0.265$; $p=0.136)$.

Because of the significant effects on global accuracy cost, we conducted post-hoc analyses to examine percent accuracy separately for single trials, repeat trials, and switch trials, adjusting for gender, education, trial accuracy at baseline, baseline serum BDNF and the BDNF genotype. For single trial accuracy, there was not a main effect of age $(B=-0.051 ; p=0.394)$ or group $(B=0.530 ; p=0.361)$ nor was there a significant age $\times$ group interaction $(B=-0.092 ; p=0.433)$. Similarly, there was not a direct effect of age $(B=-0.283 ; p=0.438)$ or group $(B=3.384$; 

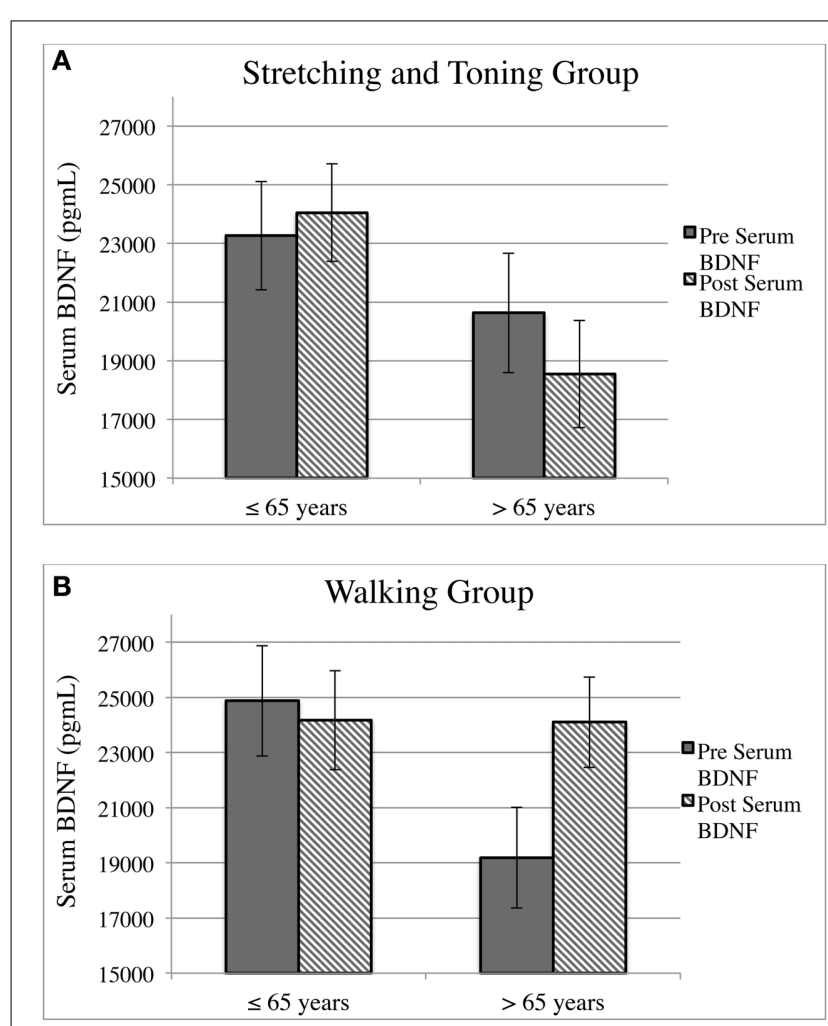

FIGURE 3 | Moderating effect of age (stratified). Note: Effects of exercise on serum BDNF as a function of age. Age stratified using a median split. (A) Serum BDNF decreases following the intervention in the control group among adults $>65$ years. (B) Serum BDNF increases following 1 year of walking exercise, specifically for adults aged $>65$ years.

$p=0.352)$ on repeat trial accuracy, or an age $\times$ group interaction term on repeat trial accuracy $(B=0.747 ; p=0.321)$. Finally, there was not an effect of age $(B=-0.075 ; p=0.832)$, group $(B=4.995 ; p=0.154)$, or their product $(B=1.126 ; p=0.124)$ on switch trial accuracy. These results suggest that the significant age $\times$ group interaction on global accuracy cost was specific to global cost, a purer measure of cognitive flexibility, rather than performance on any specific trial type.

Age did not moderate the effect of exercise on RT for any of the variables, including single RT, repeat RT, switch RT, or switch cost (all $p>0.05)$.

\section{BDNF MEDIATES EFFECT OF EXERCISE ON TASK-SWITCH PERFORMANCE AS A FUNCTION OF AGE}

The prior analyses demonstrated that the effect of exercise group on BDNF serum levels and task-switch performance varied as a function of age. Specifically, relative to the non-aerobic control condition, 12 months of moderate intensity aerobic exercise led to an increase in serum BDNF and an improvement in task performance (lower cost on global accuracy) that varied with age, with the oldest individuals showing the greatest benefits. Next, we tested whether serum BDNF mediates the association between exercise group and change in global accuracy cost following the 1-year intervention. Additionally, due to the robust age effects observed, a moderated mediation conditional processes model
Table 4 | Age moderates effect of exercise group on global task switch accuracy cost.

\begin{tabular}{lllllr}
\hline & $\boldsymbol{B}$ & $\boldsymbol{S E}$ & $\boldsymbol{p}$ & LLCI & ULCI \\
\hline COVARIATES & & & & & \\
Baseline global accuracy cost & $0.186^{*}$ & 0.085 & 0.035 & 0.039 & 0.375 \\
Baseline serum BDNF & 0.0001 & 0.0002 & 0.193 & 0.000 & 0.001 \\
BDNF genotype & 5.702 & 5.98 & 0.339 & -4.002 & 18.473 \\
Gender & 3.816 & 3.515 & 0.289 & -2.659 & 11.183 \\
Education & 2.279 & 1.297 & 0.093 & -0.249 & 4.860 \\
MAIN EFFECTS & & & & & \\
Age & -0.055 & 0.328 & 0.869 & -0.717 & 0.576 \\
Exercise group & 5.952 & 3.420 & 0.099 & -0.694 & 12.776 \\
INTERACTION & & & & & \\
Exercise group $\times$ Age & $1.645^{*}$ & 0.664 & 0.025 & 0.382 & 2.977 \\
\hline Age as moderar of the & & & & &
\end{tabular}

Age as moderator of the effect of exercise group on global accuracy cost postintervention. Coefficients are unstandardized B-values calculated from bootstrap permutation of 10,000 iterations.

LLCl, lower-level confidence interval; ULCl, upper-level confidence interval. ${ }^{*} p<0.05$.

was used to examine whether serum BDNF explained the relation between exercise group and task-switch performance as a function of age. Thus, we first examined whether serum BDNF mediated the relation between exercise group and global accuracy cost. Then, we assessed whether the mediating effect of serum BDNF varied as a function of age. For these analyses, we focused only on the task variables that showed a significant age $\times$ group interaction effect (i.e., global accuracy cost). Since gender, education, and the BDNF val66met polymorphism did not significantly modify any of the above outcomes, they were removed from subsequent mediation models.

Mediation analyses revealed that there was not a direct effect of exercise group on global accuracy cost, after accounting for baseline serum BDNF and baseline global accuracy cost $[B=4.541$; $p=0.160 ; \mathrm{CI}(\mathrm{SE})-1.831 ; 10.912(3.203)]$. In contrast, there was a significant indirect effect of exercise group on global accuracy cost through serum BDNF [ $B=1.317$; CI(SE).058; 4.66 (1.007)]. Specifically, participants in the walking group scored, on average, 1.36 percent better on global accuracy cost, which was mediated by exercise-induced changes in serum BDNF levels. The average global accuracy cost was negative $(-7.96 \%)$ indicating a smaller performance deficit between single and switch trials. Thus, 1 year of moderate-intensity aerobic exercise increased levels of serum BDNF, which, in turn, led to a decrease in cost performance.

Further, the conditional process analysis showed that there was a conditional indirect effect of exercise group on global accuracy cost through $\mathrm{BDNF}$ serum that differed by age $[B=0.168$; CI(SE).009; 0.567 (0.129)] (see Table 5). Further inspection revealed that serum $\mathrm{BDNF}$ levels mediated the relationship between exercise group and task-switch performance specifically for older aged individuals (see Figure 4).

While the above analyses included age as a continuous predictor, to determine the age at which effects of BDNF mediated task switch accuracy cost, age was divided into quintiles (10th, 25th, 50th, 75th, and 90th percentiles). Effects were then calculated for 
Table 5 | Moderated mediation model of effects of exercise group on global accuracy cost.

\begin{tabular}{lccccl}
\hline & B & SE & $\boldsymbol{p}$ & LLCl & ULCI \\
\hline COVARIATES & & & & & \\
Pre-intervention BDNF & 0.0001 & 0.0002 & 0.584 & -0.0003 & 0.0005 \\
Baseline global accuracy cost & $0.148^{*}$ & 0.062 & 0.020 & 0.024 & 0.271 \\
MODERATED MEDIATION INDIRECT EFFECT & & \\
Post-intervention BDNF & $0.168^{*}$ & 0.129 & 0.008 & 0.568 \\
Effect at 10\% Age (60 years) & -0.130 & 0.957 & -2.108 & 1.868 \\
Effect at 25\% Age (63 years) & 0.373 & 0.807 & -0.761 & 2.662 \\
Effect at 50\% Age (65 years) & 0.79 & 0.799 & -0.263 & 3.162 \\
Effect at 75\% Age (71 years) & $1.714^{*}$ & 1.183 & 0.260 & 5.382 \\
Effect at 90\% Age (76 years) & $2.553^{*}$ & 1.716 & 0.390 & 7.807 \\
\hline
\end{tabular}

Moderated mediation model displaying BDNF as mediator of the effect of exercise group on post-intervention global accuracy cost (\% correct) as a function of age. Includes overall effect and indirect effect of serum BDNF at different ages (stratified into quintiles).

${ }^{*} p<0.05$-based on confidence interval.

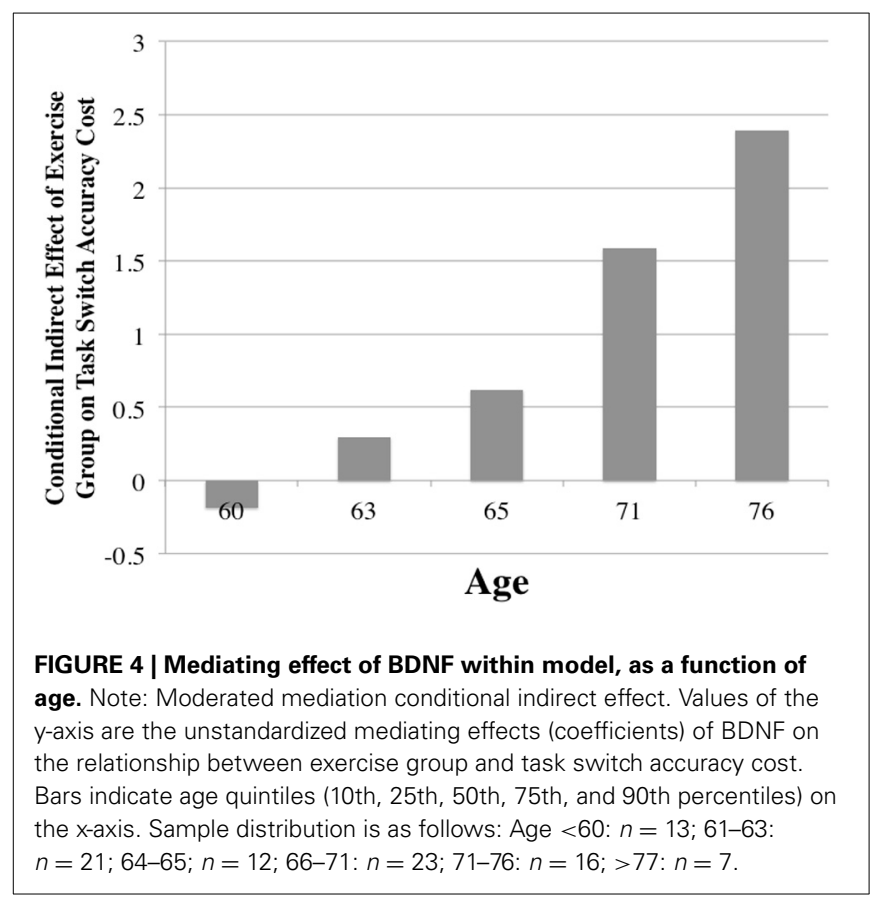

each of these percentiles of age $(60,63,65,71$, and 76 years), revealing that serum BDNF mediated the relationship between exercise group and task switch accuracy cost only among participants whose ages were in the 75 th $[B=1.714 ; \mathrm{CI}(\mathrm{SE}) 0.260 ; 5.382$ (1.183)] and 90th percentiles $[B=2.553$; $\mathrm{CI}(\mathrm{SE}) 0.390 ; 7.807$ (1.716)], or 71 years of age and older. Thus, changes in serum BDNF mediated the relationship between exercise group and task performance, specifically for participants aged 71 years and older.

\section{DISCUSSION}

In line with our hypotheses, changes in serum BDNF mediated the effect of the exercise intervention on task-switch performance.
Interestingly, this effect varied as a function of age such that only individuals older than 71 years of age showed a significant mediating effect of BDNF on task-switch performance. Of note, this relationship is significant in a regression model using baseline task-switch performance as a covariate and when examining change in a RM-ANOVA analysis. These results indicate that moderate-intensity physical activity, such as walking, may be more beneficial to both BDNF and task-switching performance for adults over the age of 70 than younger individuals.

Similar to previous research (Ziegenhorn et al., 2007; Flöel et al., 2010), our results demonstrate that older age was associated with lower BDNF serum levels. However, this relationship was not present after the 1-year intervention for the walking exercise group. Exercise increased BDNF levels, but age moderated this relationship such that older adults in the walking group showed increases in BDNF that their younger exercising group members, nor their stretching control counterparts, displayed. This moderating effect of age may account for heterogeneity in the literature that report negligible associations between longer durations of exercise and BDNF levels in middle-aged adults and in samples with a limited age range (Schulz et al., 2004; Schiffer et al., 2009).

Of particular interest, we found evidence that serum BDNF mediated the association between a 12 -month exercise intervention and improvements in executive function, but find that this mediating effect is dependent on the age of the sample. Rodent studies have also reported that BDNF mediates the effects of exercise on cognition and related brain pathways (Van Hoomissen et al., 2004; Vaynman et al., 2004; Hopkins and Bucci, 2010; Gómez-Pinilla and Feng, 2012). Yet, the current study is the first to demonstrate this effect in humans through a randomized controlled trial, and including both serum BDNF and BDNF genotype. What makes the current analyses unique is that the mediating effect of BDNF on cognition is independent of $B D N F$ genotype, and present only in adults over the age of 70 . These results highlight that age-related decreases in serum BDNF may be successfully mitigated by participation in exercise and that this might be a critical mechanism by which exercise improves executive function in late adulthood.

Our results also demonstrate that BDNF mediated the effect of exercise on task-switch accuracy cost, but not on response time, in adults aged 70 years or older. Accuracy on the task-switch paradigm is often interpreted as a measure of executive function ability to execute the task demands, while response times are interpreted as a measure of cognitive control, processing speed or efficiency (Hughes et al., 2013). Thus, our results demonstrate that the effects of exercise on the ability to execute the demands of a challenging task that taps into executive functions are mediated by BDNF in adults over the age of 70 . We can only speculate as to the reason for the non-significant effects on response times. One possibility is that there are selective effects of BDNF on the neural correlates that support accuracy verses response times (Hughes et al., 2013). Specifically, BDNF may be mediating the effect of exercise on the prefrontal and parietal regions that support executive function (Jimura et al., 2014) and the "top-down" processing required for task-switch accuracy (Phillips et al., 2013), and not the striatum or regions which are associated with processing speed or response time outcomes (Jimura et al., 2014). Still, our 
results suggest that the modification in the level of serum BDNF is an important pathway by which exercise influences executive function for adults over 70 years of age.

Despite the strengths of our study, there remain several important limitations. First, analyses and interpretation of the results are based on serum BDNF levels, rather than BDNF directly from brain tissue. Importantly, rodent studies have found significant correlations between cortical BDNF and circulating BDNF levels (Karege et al., 2002), despite controversy on the validity of serum BDNF as a proxy for cortical concentrations (Knaepen et al., 2010). Thus, we believe that this is an acceptable limitation given the obvious challenges of obtaining brain tissue from human subjects. Additionally, while the sample size of each intervention group is similar-to or larger-than previous randomized clinical trials, the statistical models employed in the current analyses limit degrees of freedom and require a large sample to detect effects. It is possible that a larger sample would strengthen current findings or reveal effects in younger ages. Additionally, the current sample was mostly female with little representation of racial minorities, preventing generalization to a population outside of female Caucasians. Finally, our sample was relatively homogeneous without outward signs of cognitive impairment. Therefore, a more varied sample with different demographic characteristics and cognitive abilities may find different results than those described here.

The current findings indicate that adults over the age of 70 may gain the most from aerobic exercise in terms of both serum BDNF and task-switch performance. Indeed, the current sample shows no significant difference in BDNF serum levels or task switch performance at follow-up between the control and exercise intervention groups, however when examined as a function of age, BDNF levels significantly mediate the effect of exercise group on improvements in executive function. The results from this study do not preclude positive effects of exercise on other cognitive domains, other age ranges, other populations, or other putative mechanistic pathways (i.e., inflammatory). These findings highlight the importance of considering both age and BDNF when designing exercise interventions and interpreting the mechanism by which exercise improves cognitive performance, particularly in the elderly.

\section{REFERENCES}

Adlard, P. A., Perreau, V. M., and Cotman, C. W. (2005). The exercise-induced expression of BDNF within the hippocampus varies across life-span. Neurobiol. Aging 26, 511-520. doi: 10.1016/j.neurobiolaging.2004.05.006

Aguiar, A. S. Jr., Castro, A. A., Moreira, E. L., Glaser, V., Santos, A. R., Tasca, C. I., et al. (2011). Short bouts of mild-intensity physical exercise improve spatial learning and memory in aging rats: involvement of hippocampal plasticity via AKT, CREB and BDNF signaling. Mech. Ageing Dev. 132, 560-567. doi: 10.1016/j.mad.2011.09.005

Albert, M. S., Jones, K., Savage, C. R., Berkman, L., Seeman, T., Blazer, D., et al. (1995). Predictors of cognitive change in older persons: MacArthur studies of successful aging. Psychol. Aging 10, 578. doi: 10.1037/0882-7974.10.4.578

Aron, A. R., Monsell, S., Sahakian, B. J., and Robbins, T. W. (2004). A componential analysis of task-switching deficits associated with lesions of left and right frontal cortex. Brain 127, 1561-1573. doi: 10.1093/brain/awh169

Baker, L. D., Frank, L. L., Foster-Schubert, K., Green, P. S., Wilkinson, C. W., McTiernan, A., et al. (2010). Effects of aerobic exercise on mild cognitive impairment: a controlled trial. Arch. Neurol. 67, 71-79. doi: 10.1001/archneurol.2009.307
Bechara, R. G., and Kelly, A. M. (2013). Exercise improves object recognition memory and induces BDNF expression and cell proliferation in cognitively enriched rats. Behav. Brain Res. 245, 96-100. doi: 10.1016/j.bbr.2013.02.018

Bekinschtein, P., Cammarota, M., and Medina, J. H. (2014). BDNF and memory processing. Neuropharmacology 76(Pt C), 677-683. doi: 10.1016/j.neuropharm.2013.04.024

Benedict, C., Brooks, S. J., Kullberg, J., Nordenskjöld, R., Burgos, J., Le Grevès, M., et al. (2013). Association between physical activity and brain health in older adults. Neurobiol. Aging 34, 83-90. doi: 10.1016/j.neurobiolaging.2012.04.013

Bishop, N. A., Lu, T., and Yankner, B. A. (2010). Neural mechanisms of ageing and cognitive decline. Nature 464, 529-535. doi: 10.1038/nature08983

Borg, G. (1985). An Introduction to Borg's RPE-scale. Ithaca, NY: Mouvement Publications.

Braver, T. S., Reynolds, J. R., and Donaldson, D. I. (2003). Neural mechanisms of transient and sustained cognitive control during task switching. Neuron 39, 713-726. doi: 10.1016/S0896-6273(03)00466-5

Burke, S. N., and Barnes, C. A. (2006). Neural plasticity in the ageing brain. Nat. Rev. Neurosci. 7, 30-40. doi: 10.1038/nrn1809

Cepeda, N. J., Kramer, A. F., and Gonzalez de Sather, J. (2001). Changes in executive control across the life span: examination of task-switching performance. Dev. Psychol. 37, 715. doi: 10.1037/0012-1649.37.5.715

Coelho, F. G. D. M., Gobbi, S., Andreatto, C. A. A., Corazza, D. I., Pedroso, R. V., and Santos-Galduróz, R. F. (2013). Physical exercise modulates peripheral levels of brain-derived neurotrophic factor (BDNF): a systematic review of experimental studies in the elderly. Arch. Gerontol. Geriatr. 56, 10-15. doi: 10.1016/j.archger.2012.06.003

Colcombe, S. J., Erickson, K. I., Raz, N., Webb, A. G., Cohen, N. J., McAuley, E., et al. (2003). Aerobic fitness reduces brain tissue loss in aging humans. J. Gerontol. A Biol. Sci. Med. Sci. 58, 176-180. doi: 10.1093/gerona/58.2.M176

Colcombe, S. J., Erickson, K. I., Scalf, P. E., Kim, J. S., Prakash, R., McAuley, E., et al. (2006). Aerobic exercise training increases brain volume in aging humans. J. Gerontol. A Biol. Sci. Med. Sci. 61, 1166-1170. doi: 10.1093/gerona/61. 11.1166

Colcombe, S., and Kramer, A. F. (2003). Fitness effects on the cognitive function of older adults: a meta-analytic study. Psychol. Sci. 14, 125-130. doi: 10.1111/14679280.t01-1-01430

Creer, D. J., Romberg, C., Saksida, L. M., van Praag, H., and Bussey, T. J. (2010). Running enhances spatial pattern separation in mice. Proc. Natl. Acad. Sci. U.S.A. 107, 2367-2372. doi: 10.1073/pnas.0911725107

Diógenes, M. J., Costenla, A. R., Lopes, L. V., Jerónimo-Santos, A., Sousa, V. C., Fontinha, B. M., et al. (2011). Enhancement of LTP in aged rats is dependent on endogenous BDNF. Neuropsychopharmacology 36, 1823-1836. doi: 10.1038/npp.2011.64

Driscoll, I., Davatzikos, C., An, Y., Wu, X., Shen, D., Kraut, M., et al. (2009). Longitudinal pattern of regional brain volume change differentiates normal aging from MCI. Neurology 72, 1906-1913. doi: 10.1212/WNL.0b013e3181a82634

Driscoll, I., Martin, B., An, Y., Maudsley, S., Ferrucci, L., Mattson, M. P., et al. (2012). Plasma BDNF is associated with age-related white matter atrophy but not with cognitive function in older, non-demented adults. PLoS ONE 7:e35217. doi: 10.1371/journal.pone.0035217

El Haj, M., and Allain, P. (2012). Relationship between source monitoring in episodic memory and executive function in normal aging. Geriatr. Psychol. Neuropsychiatr. Vieil. 10, 197-205. doi: 10.1684/pnv.2012.0342

Erickson, K. I., Kim, J. S., Suever, B. L., Voss, M. W., Francis, B. M., and Kramer, A. F. (2008). Genetic contributions to age-related decline in executive function: a 10-year longitudinal study of COMT and BDNF polymorphisms. Front. Hum. Neurosci. 2:11. doi: 10.3389/neuro.09.011.2008

Erickson, K. I., Prakash, R. S., Voss, M. W., Chaddock, L., Heo, S., McLaren, M., et al. (2010a). Brain-derived neurotrophic factor is associated with age-related decline in hippocampal volume. J. Neurosci. 30, 5368-5375. doi: 10.1523/JNEUROSCI.6251-09.2010

Erickson, K. I., Raji, C. A., Lopez, O. L., Becker, J. T., Rosano, C., Newman, A. B., et al. (2010b). Physical activity predicts gray matter volume in late adulthood: the cardiovascular health study. Neurology 75, 1415-1422. doi: 10.1212/WNL.0b013e3181f88359

Erickson, K. I., Voss, M. W., Prakash, R. S., Basak, C., Szabo, A., Chaddock, L., et al. (2011). Exercise training increases size of hippocampus and improves memory. Proc. Natl. Acad. Sci. U.S.A. 108, 3017-3022. doi: 10.1073/pnas.1015950108 
Erickson, K. I., Weinstein, A. M., Sutton, B. P., Prakash, R. S., Voss, M. W., Chaddock, L., et al. (2012). Beyond vascularization: aerobic fitness is associated with $\mathrm{N}$-acetylaspartate and working memory. Brain Behav. 2, 32-41. doi: 10.1002/brb3.30

Etnier, J. L., Caselli, R. J., Reiman, E. M., Alexander, G. E., Sibley, B. A., Tessier, D., et al. (2007). Cognitive performance in older women relative to ApoEepsilon4 genotype and aerobic fitness. Med. Sci. Sports Exerc. 39, 199-207. doi: 10.1249/01.mss.0000239399.85955.5e

Flöel, A., Ruscheweyh, R., Krüger, K., Willemer, C., Winter, B., Völker, K., et al. (2010). Physical activity and memory functions: are neurotrophins and cerebral gray matter volume the missing link? Neuroimage 49, 2756-2763. doi: 10.1016/j.neuroimage.2009.10.043

Gazes, Y., Rakitin, B. C., Habeck, C., Steffener, J., and Stern, Y. (2012). Age differences of multivariate network expressions during task-switching and their associations with behavior. Neuropsychologia 50, 3509-3518. doi: 10.1016/j.neuropsychologia.2012.09.039

Gold, B. T., Powell, D. K., Xuan, L., Jicha, G. A., and Smith, C. D. (2010). Age-related slowing of task switching is associated with decreased integrity of frontoparietal white matter. Neurobiol. Aging 31, 512-522. doi: 10.1016/j.neurobiolaging.2008.04.005

Gómez-Pinilla, F., and Feng, C. (2012). "Molecular mechanisms for the ability of exercise supporting cognitive abilities and counteracting neurological disorders," in Functional Neuroimaging in Exercise and Sport Sciences, eds H. Boecker, C. H. Hillman, L. Scheef, and H. K. Strüder (New York, NY: Springer), 25-43.

Gómez-Pinilla, F., Ying, Z., Roy, R. R., Molteni, R., and Edgerton, V. R. (2002). Voluntary exercise induces a BDNF-mediated mechanism that promotes neuroplasticity. J. Neurophysiol. 88, 2187-2195. doi: 10.1152/jn.00152.2002

Gons, R. A., Tuladhar, A. M., de Laat, K. F., van Norden, A. G., van Dijk, E. J., Norris, D. G., et al. (2013). Physical activity is related to the structural integrity of cerebral white matter. Neurology 81, 971-976. doi: 10.1212/WNL.0b013e3182a43e33

Gow, A. J., Bastin, M. E., Maniega, S. M., Hernández, M. C. V., Morris, Z., Murray, C., et al. (2012). Neuroprotective lifestyles and the aging brain: activity, atrophy, and white matter integrity. Neurology 79, 1802-1808. doi: 10.1212/WNL.0b013e3182703fd2

Gratton, G., Wee, E., Rykhlevskaia, E. I., Leaver, E. E., and Fabiani, M. (2009). Does white matter matter? Spatio-temporal dynamics of task switching in aging. $J$. Cogn. Neurosci. 21, 1380-1395. doi: 10.1162/jocn.2009.21093

Gunstad, J., Benitez, A., Smith, J., Glickman, E., Spitznagel, M. B., Alexander, T., et al. (2008). Serum brain-derived neurotrophic factor is associated with cognitive function in healthy older adults. J. Geriatr. Psychiatry Neurol. 21, 166-170. doi: $10.1177 / 0891988708316860$

Hayes, A. F. (2013). "Introduction to mediation, moderation, and conditional process analysis," in Methodology in the Social Sciences, ed T. D. Little (New York, NY: Guilford Press), 3-415.

Heyman, E., Gamelin, F. X., Goekint, M., Piscitelli, F., Roelands, B., Leclair, E., et al. (2012). Intense exercise increases circulating endocannabinoid and BDNF levels in humans-possible implications for reward and depression. Psychoneuroendocrinology 37, 844-851. doi: 10.1016/j.psyneuen.2011.09.017

Hopkins, M. E., and Bucci, D. J. (2010). BDNF expression in perirhinal cortex is associated with exercise-induced improvement in object recognition memory. Neurobiol. Learn. Mem. 94, 278-284. doi: 10.1016/j.nlm.2010. 06.006

Hughes, M. M., Linck, J. A., Bowles, A. R., Koeth, J. T., and Bunting, M. F. (2013). Alternatives to switch-cost scoring in the task-switching paradigm: their reliability and increased validity. Behav. Res. Methods 46, 702-721. doi: 10.3758/ s13428-013-0411-5

Jimura, K., and Braver, T. S. (2010). Age-related shifts in brain activity dynamics during task switching. Cereb. Cortex 20, 1420-1431. doi: 10.1093/cercor/bhp206

Jimura, K., Cazalis, F., Stover, E. R., and Poldrack, R. A. (2014). The neural basis of task switching changes with skill acquisition. Front. Hum. Neurosci. 8:339. doi: 10.3389/fnhum.2014.00339

Karege, F., Schwald, M., and Cisse, M. (2002). Postnatal developmental profile of brain-derived neurotrophic factor in rat brain and platelets. Neurosci. Lett. 328, 261-264. doi: 10.1016/S0304-3940(02)00529-3

Knaepen, K., Goekint, M., Heyman, E. M., and Meeusen, R. (2010). Neuroplasticity-exercise-induced response of peripheral brain-derived neurotrophic factor: a systematic review of experimental studies in human subjects. Sports Med. 40, 765-801. doi: 10.2165/11534530-000000000-00000
Kramer, A. F., Hahn, S., Cohen, N. J., Banich, M. T., McAuley, E., Harrison, C. R., et al. (1999a). Ageing, fitness and neurocognitive function. Nature 400, 418-419. doi: $10.1038 / 22682$

Kramer, A. F., Hahn, S., and Gopher, D. (1999b). Task coordination and aging: explorations of executive control processes in the task switching paradigm. Acta Psychol. 101, 339-378. doi: 10.1016/S0001-6918(99)00011-6

Kray, J., and Lindenberger, U. (2000). Adult age differences in task switching. Psychol. Aging 15:126. doi: 10.1037/0882-7974.15.1.126

Lang, U. E., Hellweg, R., Sander, T., and Gallinat, J. (2009). The Met allele of the BDNF Val66Met polymorphism is associated with increased BDNF serum concentrations. Mol. Psychiatry 14, 120-122. doi: 10.1038/mp.2008.80

Larson, E. B., Wang, L., Bowen, J. D., McCormick, W. C., Teri, L., Crane, P., et al. (2006). Exercise is associated with reduced risk for incident dementia among persons 65 years of age and older. Ann. Intern. Med. 144, 73-81. doi: 10.7326/0003-4819-144-2-200601170-00004

Li, S. C., Lindenberger, U., and Sikstrom, S. (2001). Aging cognition: from neuromodulation to representation. Trends Cogn. Sci. 5, 479-486. doi: 10.1016/S13646613(00)01769-1

Li, Y., Luikart, B. W., Birnbaum, S., Chen, J., Kwon, C. H., Kernie, S. G., et al. (2008). TrkB regulates hippocampal neurogenesis and governs sensitivity to antidepressive treatment. Neuron 59, 399-412. doi: 10.1016/j.neuron.2008.06.023

Lommatzsch, M., Zingler, D., Schuhbaeck, K., Schloetcke, K., Zingler, C., SchuffWerner, P., et al. (2005). The impact of age, weight and gender on BDNF levels in human platelets and plasma. Neurobiol. Aging 26, 115-123. doi: 10.1016/j.neurobiolaging.2004.03.002

Lu, B. (2003). BDNF and activity-dependent synaptic modulation. Learn. Mem. 10, 86-98. doi: 10.1101/lm.54603

Marais, L., Stein, D. J., and Daniels, W. M. (2009). Exercise increases BDNF levels in the striatum and decreases depressive-like behavior in chronically stressed rats. Metab. Brain Dis. 24, 587-597. doi: 10.1007/s11011-009-9157-2

McAuley, E., Mullen, S. P., Szabo, A. N., White, S. M., Wójcicki, T. R., Mailey, E. L., et al. (2011). Self-regulatory processes and exercise adherence in older adults: executive function and self-efficacy effects. Am. J. Prev. Med. 41, 284-290. doi: 10.1016/j.amepre.2011.04.014

Neeper, S. A., Gómez-Pinilla, F., Choi, J., and Cotman, C. W. (1996). Physical activity increases mRNA for brain-derived neurotrophic factor and nerve growth factor in rat brain. Brain Res. 726, 49-56. doi: 10.1016/0006-8993(96)00273-9

Oldfield, R. C. (1971). The assessment and analysis of handedness: the Edinburgh inventory. Neuropsychologia 9, 97-113. doi: 10.1016/0028-3932(71)90067-4

Oliff, H. S., Berchtold, N. C., Isackson, P., and Cotman, C. W. (1998). Exerciseinduced regulation of brain-derived neurotrophic factor (BDNF) transcripts in the rat hippocampus. Brain Res. Mol. Brain Res. 61, 147-153. doi: 10.1016/S0169-328X(98)00222-8

Pang, P. T., and Lu, B. (2004). Regulation of late-phase LTP and long-term memory in normal and aging hippocampus: role of secreted proteins tPA and BDNF. Ageing Res. Rev. 3, 407-430. doi: 10.1016/j.arr.2004.07.002

Phillips, J. M., Vinck, M., Everling, S., and Womelsdorf, T. (2013). A long-range fronto-parietal 5- to $10-\mathrm{Hz}$ network predicts "Top-Down" controlled guidance in a task-switch paradigm. Cereb. Cortex 24, 1996-2008. doi: 10.1093/cercor/ bht050

Podewils, L. J., Guallar, E., Kuller, L. H., Fried, L. P., Lopez, O. L., Carlson, M., et al. (2005). Physical activity, APOE genotype, and dementia risk: findings from the Cardiovascular Health Cognition Study. Am. J. Epidemiol. 161, 639-651. doi: 10.1093/aje/kwi092

Ruscheweyh, R., Willemer, C., Krüger, K., Duning, T., Warnecke, T., Sommer, J., et al. (2011). Physical activity and memory functions: an interventional study. Neurobiol. Aging 32, 1304-1319. doi: 10.1016/j.neurobiolaging.2009. 08.001

Salat, D. H., Tuch, D. S., Greve, D. N., Van Der Kouwe, A. J. W., Hevelone, N. D., Zaleta, A. K., et al. (2005). Age-related alterations in white matter microstructure measured by diffusion tensor imaging. Neurobiol. Aging 26, 1215-1227. doi: 10.1016/j.neurobiolaging.2004.09.017

Salthouse, T. A., Fristoe, N., McGuthry, K. E., and Hambrick, D. Z. (1998). Relation of task switching to speed, age, and fluid intelligence. Psychol. Aging 13:445. doi: 10.1037/0882-7974.13.3.445

Schiffer, T., Schulte, S., Hollmann, W., Bloch, W., and Strüder, H. K. (2009). Effects of strength and endurance training on brain-derived neurotrophic factor and insulin-like growth factor 1 in humans. Horm. Metab. Res. 41, 250-254. doi: $10.1055 /$ s-0028-1093322 
Schmidt, R., Schmidt, H., Curb, J. D., Masaki, K., White, L. R., and Launer, L. J. (2002). Early inflammation and dementia: a 25-year follow-up of the HonoluluAsia Aging Study. Ann. Neurol. 52, 168-174. doi: 10.1002/ana.10265

Schulz, K. H., Gold, S. M., Witte, J., Bartsch, K., Lang, U. E., Hellweg, R., et al. (2004). Impact of aerobic training on immune-endocrine parameters, neurotrophic factors, quality of life and coordinative function in multiple sclerosis. J. Neurol. Sci. 225, 11-18. doi: 10.1016/j.jns.2004.06.009

Silver, H., Goodman, C., Gur, R. C., Gur, R. E., and Bilker, W. B. (2011). 'Executive' functions and normal aging: selective impairment in conditional exclusion compared to abstraction and inhibition. Dement. Geriatr. Cogn. Disord. 31, 53-62. doi: 10.1159/000322568

Singh, T., and Newman, A. B. (2011). Inflammatory markers in population studies of aging. Ageing Res. Rev. 10, 319-329. doi: 10.1016/j.arr.2010.11.002

Singh-Manoux, A., Kivimaki, M., Glymour, M. M., Elbaz, A., Berr, C., Ebmeier, K. P., et al. (2012). Timing of onset of cognitive decline: results from Whitehall II prospective cohort study. BMJ 344, d7622. doi: 10.1136/bmj.d7622

Smith, J. C., Nielson, K. A., Woodard, J. L., Seidenberg, M., Durgerian, S., Hazlett, K. E., et al. (2014). Physical activity reduces hippocampal atrophy in elders at genetic risk for Alzheimer's disease. Front. Aging Neurosci. 6:61. doi: 10.3389/fnagi.2014.00061

Smith, P. J., Blumenthal, J. A., Hoffman, B. M., Cooper, H., Strauman, T. A., WelshBohmer, K., et al. (2010). Aerobic exercise and neurocognitive performance: a meta-analytic review of randomized controlled trials. Psychosom. Med. 72, 239-252. doi: 10.1097/PSY.0b013e3181d14633

Sofi, F., Valecchi, D., Bacci, D., Abbate, R., Gensini, G. F., Casini, A., et al. (2011). Physical activity and risk of cognitive decline: a meta-analysis of prospective studies. J. Intern. Med. 269, 107-117. doi: 10.1111/j.1365-2796.2010.02281.x

Sohn, M. H., Ursu, S., Anderson, J. R., Stenger, V. A., and Carter, C. S. (2000). The role of prefrontal cortex and posterior parietal cortex in task switching. Proc. Natl. Acad. Sci. U.S.A. 97, 13448-13453. doi: 10.1073/pnas.240460497

Sowell, E. R., Peterson, B. S., Thompson, P. M., Welcome, S. E., Henkenius, A. L., and Toga, A. W. (2003). Mapping cortical change across the human life span. Nat. Neurosci. 6, 309-315. doi: 10.1038/nn1008

Stern, Y., Sano, M., Paulson, J., and Mayeux, R. (1987). Modified mini-mental state examination: validity and reliability. Neurology 37, 179.

Stranahan, A. M., Lee, K., Martin, B., Maudsley, S., Golden, E., Cutler, R. G., et al. (2009). Voluntary exercise and caloric restriction enhance hippocampal dendritic spine density and BDNF levels in diabetic mice. Hippocampus 19, 951-961. doi: 10.1002/hipo.20577

Strath, S. J., Swartz, A. M., Bassett, D. R. Jr., O’Brien, W. L., King, G. A., and Ainsworth, B. E. (2000). Evaluation of heart rate as a method for assessing moderate intensity physical activity. Med. Sci. Sports Exerc. 32, S465-S470. doi: 10.1097/00005768-200009001-00005

Ströhle, A., Stoy, M., Graetz, B., Scheel, M., Wittmann, A., Gallinat, J., et al. (2010). Acute exercise ameliorates reduced brain-derived neurotrophic factor in patients with panic disorder. Psychoneuroendocrinology 35, 364-368. doi: 10.1016/j.psyneuen.2009.07.013

Tian, Q., Erickson, K. I., Simonsick, E. M., Aizenstein, H. J., Glynn, N. W., Boudreau, R. M., et al. (2014). Physical activity predicts microstructural integrity in memory-related networks in very old adults. J. Gerontol. A Biol. Sci. Med. Sci. 69, 1284-1290. doi: 10.1093/gerona/glt287

Van Hoomissen, J. D., Holmes, P. V., Zellner, A. S., Poudevigne, A., and Dishman, R. K. (2004). Effects of beta-adrenoreceptor blockade during chronic exercise on contextual fear conditioning and mRNA for galanin and brain-derived neurotrophic factor. Behav. Neurosci. 118, 1378-1390. doi: 10.1037/07357044.118.6.1378

Van Praag, H., Shubert, T., Zhao, C., and Gage, F. H. (2005). Exercise enhances learning and hippocampal neurogenesis in aged mice. J. Neurosci. 25, 8680-8685. doi: 10.1523/JNEUROSCI.1731-05.2005

Vaynman, S., Ying, Z., and Gomez-Pinilla, F. (2004). Hippocampal BDNF mediates the efficacy of exercise on synaptic plasticity and cognition. Eur. J. Neurosci. 20, 2580-2590. doi: 10.1111/j.1460-9568.2004.03720.x
Verstynen, T. D., Lynch, B., Miller, D. L., Voss, M. W., Prakash, R. S., Chaddock, L., et al. (2012). Caudate nucleus volume mediates the link between cardiorespiratory fitness and cognitive flexibility in older adults. J. Aging Res. 2012, 939285. doi: 10.1155/2012/939285

Voss, M. W., Erickson, K. I., Prakash, R. S., Chaddock, L., Kim, J. S., Alves, H., et al. (2013). Neurobiological markers of exercise-related brain plasticity in older adults. Brain Behav. Immun. 28, 90-99. doi: 10.1016/j.bbi.2012.10.021

Voss, M. W., Erickson, K. I., Prakash, R. S., Chaddock, L., Malkowski, E., Alves, H., et al. (2010b). Functional connectivity: a source of variance in the association between cardiorespiratory fitness and cognition? Neuropsychologia 48, 1394-1406. doi: 10.1016/j.neuropsychologia.2010.01.005

Voss, M. W., Prakash, R. S., Erickson, K. I., Basak, C., Chaddock, L., Kim, J. S., et al. (2010a). Plasticity of brain networks in a randomized intervention trial of exercise training in older adults. Front. Aging Neurosci. 2:32. doi: 10.3389/fnagi.2010.00032

Wang, J., Chuang, K., Ahluwalia, M., Patel, S., Umblas, N., Mirel, D., et al. (2005). High-throughput SNP genotyping by single-tube PCR with T m-shift primers. Biotechniques 39, 885. doi: 10.2144/000112028

Weinstein, A. M., Voss, M. W., Prakash, R. S., Chaddock, L., Szabo, A., White, S. M., et al. (2012). The association between aerobic fitness and executive function is mediated by prefrontal cortex volume. Brain Behav. Immun. 26, 811-819. doi: 10.1016/j.bbi.2011.11.008

Woodard, J. L., Nielson, K. A., Sugarman, M. A., Smith, J. C., Seidenberg, M., Durgerian, S., et al. (2012). Lifestyle and genetic contributions to cognitive decline and hippocampal structure and function in healthy aging. Curr. Alzheimer Res. 9, 436-446. doi: 10.2174/156720512800492477

Yang, J. L., Lin, Y. T., Chuang, P. C., Bohr, V. A., and Mattson, M. P. (2014). BDNF and exercise enhance neuronal DNA repair by stimulating CREB-mediated production of apurinic/apyrimidinic endonuclease 1. Neuromolecular Med. 16, 161-174. doi: 10.1007/s12017-013-8270-x

Yesavage, J. A., and Sheikh, J. I. (1986). 9/Geriatric depression scale (GDS) recent evidence and development of a shorter violence. Clin. Gerontol. 5, 165-173. doi: 10.1300/J018v05n01_09

Ziegenhorn, A. A., Schulte-Herbrüggen, O., Danker-Hopfe, H., Malbranc, M., Hartung, H. D., Anders, D., et al. (2007). Serum neurotrophins-a study on the time course and influencing factors in a large old age sample. Neurobiol. Aging 28, 1436-1445. doi: 10.1016/j.neurobiolaging.2006.06.011

Zoladz, J. A., and Pilc, A. (2010). The effect of physical activity on the brain derived neurotrophic factor: from animal to human studies. J. Physiol. Pharmacol. 61, 533-541.

Conflict of Interest Statement: The authors declare that the research was conducted in the absence of any commercial or financial relationships that could be construed as a potential conflict of interest.

Received: 05 August 2014; paper pending published: 26 October 2014; accepted: 18 November 2014; published online: 11 December 2014.

Citation: Leckie RL, Oberlin LE, Voss MW, Prakash RS, Szabo-Reed A, ChaddockHeyman L, Phillips SM, Gothe NP, Mailey E, Vieira-Potter VJ, Martin SA, Pence BD, Lin M, Parasuraman R, Greenwood PM, Fryxell KJ, Woods JA, McAuley E, Kramer AF and Erickson KI (2014) BDNF mediates improvements in executive function following a 1-year exercise intervention. Front. Hum. Neurosci. 8:985. doi: 10.3389/fnhum. 2014.00985

This article was submitted to the journal Frontiers in Human Neuroscience.

Copyright (C) 2014 Leckie, Oberlin, Voss, Prakash, Szabo-Reed, Chaddock-Heyman, Phillips, Gothe, Mailey, Vieira-Potter, Martin, Pence, Lin, Parasuraman, Greenwood, Fryxell, Woods, McAuley, Kramer and Erickson. This is an open-access article distributed under the terms of the Creative Commons Attribution License (CC BY). The use, distribution or reproduction in other forums is permitted, provided the original author(s) or licensor are credited and that the original publication in this journal is cited, in accordance with accepted academic practice. No use, distribution or reproduction is permitted which does not comply with these terms. 